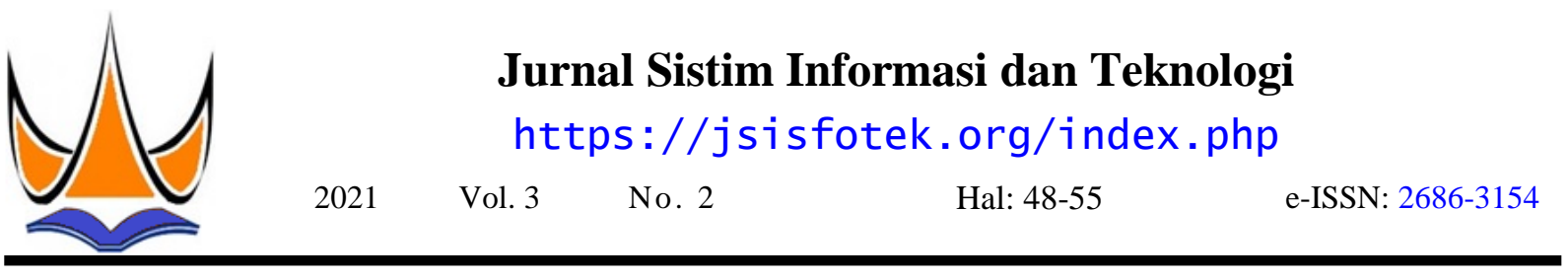

\title{
Sistem Pakar Menggunakan Metode Certainty Factor dalam Identifikasi Pengembangan Minat dan Bakat Khusus pada Siswa
}

\author{
Nandra Sunaryo ${ }^{1 凶}$, Yuhandri Yunus ${ }^{2}$, Sumijan $^{3}$ \\ ${ }^{1,2,3}$ Universitas Putra Indonesia YPTK Padang \\ nandra997@gmai1.com
}

\begin{abstract}
Identification of the development of special interests and talents needs to be done in order to find out the potential of students. This knowledge is needed by the teacher when providing counseling guidance to students in order to know the types of special interests and talents of students. This study aims to identify the development of special interests and talents in students based on the characteristics of special interests and talents appropriately. In this study using the Certainty Factor method where this expert system can assist experts in identifying the development of special interests and talents based on the characteristics of special interests and talents in students. Followed by calculating the level of accuracy with the results of the counseling guidance teacher analysis. The results of the testing of the Certainty Factor method were successfully applied by comparing the data with the system that had been designed so that a good level of accuracy was obtained from the results of the system calculations with expert decisions of $80 \%$ of the 5 test data. This expert system application can be used as an alternative in identifying the development of special interests and talents in students.
\end{abstract}

Keywords: Expert System, Special Interests and Talents, Counseling Guidance, Certainty Factors, Student.

\begin{abstract}
Abstrak
Identifikasi pengembangan minat dan bakat khusus perlu dilakukan agar dapat mengetahui potensi siswa. Pengetahuan itu diperlukan guru saat memberikan bimbingan konseling kepada siswa agar mengetahui jenis minat dan bakat khusus siswa. Penelitian ini bertujuan untuk identifikasi pengembangan minat dan bakat khusus pada siswa berdasarkan ciri-ciri minat dan bakat khusus secara tepat. Pada penelitian ini menggunakan metode Certainty Factor dimana sistem pakar ini dapat membantu pakar dalam identifikasi pengembangan minat dan bakat khusus berdasarkan ciri-ciri minat dan bakat khusus pada siswa. Dilanjutkan penghitungan tingkat akurasinya dengan hasil analisis guru bimbingan konseling. Hasil dari pengujian terhadap metode Certainty Factor berhasil diterapkan dengan membandingkan data dengan sistem yang sudah dirancang maka didapatkan tingkat akurasi yang baik dari hasil perhitungan sistem dengan keputusan pakar sebesar $80 \%$ dari 5 data pengujian. Aplikasi sistem pakar ini dapat dijadikan alternatif dalam identifikasi pengembangan minat dan bakat khusus pada siswa.
\end{abstract}

Kata kunci: Sistem Pakar, Minat dan Bakat Khusus, Bimbingan Konseling, Certainty Factor, Siswa.

(C) 2021 JSisfotek

\section{Pendahuluan}

Perkembangan teknologi informasi dan komunikasi semakin banyak dimanfaatkan dalam berbagai bidang dan aspek kehidupan. Tidak dipungkiri saat ini hampir setiap segi kehidupan kita telah terkait dengan teknologi. Hal ini terjadi karena memberikan kemudahan dan menciptakan efisiensi manusia dalam menyelesaikan suatu pekerjaannya. Salah satu bidang yang banyak memperoleh manfaat dari perkembangan ilmu pengetahuan dan teknologi tersebut adalah bidang pendidikan. Pendidikan merupakan usaha sadar dan terencana agar terwujudnya suasana belajar dan proses pembelajaran secara aktif dan kritis dalam berpikir untuk mengembangkan potensi diri, pengendalian diri, kepribadian, kecerdasan, keterampilan, serta untuk dapat mengerti dan paham dalam spiritual keagamaan agar membuat manusia lebih baik [1].

Potensi minat dan bakat yang dimiliki oleh setiap anak tidaklah sama. Potensi merupakan suatu kemampuan dasar yang spesifik dimiliki oleh seorang anak, sedangkan minat merupakan keinginan seseorang untuk memilih sesuatu yang disukai, sedangkan bakat dapat diartikan sebagai kecerdasan dan kemampuan bawaan itu dari lahir [2]. Melakukan penentuan minat dan bakat sangat perlu dilakukan agar dapat mengetahui potensi peserta didik, baik dalam segi akademis maupun nonakademis. Pengetahuan itu sangat diperlukan saat memberikan pendampingan dan pengembangan keterampilan yang sesuai bakat yang dimiliki oleh peserta didik. Keterampilan perlu dikembangkan sejak dini agar peserta didik dapat mengoptimalkan bakat yang ada pada dirinya, sehingga peserta didik dapat bersaing pada saat setelah lulus sekolah terutama di dunia kerja. Melakukan penentuan bakat dan minat dapat menentukan arah yang tepat dalam pemilihan studi dan pengembangan diri untuk mendapatkan kompetensi dan keterampilan yang dibutuhkan oleh peserta didik [3].

Sistem pakar dalam mengambil keputusan sama cara kerjanya dengan seorang pakar. Sistem pakar merupakan sebuah program komputer yang memiliki

Diterima: 16-10-2020 | Revisi: 31-10-2020 | Diterbitkan: 30-06-2021 | DOI: 10.37034/jsisfotek.v3i2.43 
pengetahuan layaknya sama seperti seorang pakar. tersebut. Sistem pakar juga dapat digunakan sebagai Seorang pakar dapat digantikan perannya oleh program alternatif menjadi asisten seorang pakar dalam computer yang prinsip kerjanya untuk memberikan membantu kinerja seorang pakar [6].

solusi seperti yang dilakukan oleh sistem pakar dan system ini tidak dapat berkerja sendiri tanpa 2.3. Metode Certainty Factor menggunakan sebuah metode [4]. Alasan diadakannya penelitian ini adalah untuk membatu guru bimbingan konseling dalam melakukakan konseling pada siswa mengingat waktu jam pembelajaran bimbingan konseling tidak cukup. Guru bimbingan konseling akan membantu siswa dalam identifikasi pengembangan minat dan bakat khusus yang ada pada diri siswa dengan menentukan ciri-ciri minat dan bakat khusus pada siswa, setelah itu guru akan menentukan minat dan bakat khusus apa yang cocok untuk siswa tersebut, guru juga akan memberikan stimulasi sesuai dengan jenis minat dan bakat khusus yang tepat bagi siswa, agar siswa tersebut dapat mengembangkan potensi dirinya dan menentukan minat dan bakat khusus apa yang cocok untuk siswa tersebut.

Guna tercapainya bimbingan konseling yang cepat dan tepat maka perlu dilakukan perancangan sistem pakar untuk menentukan identifikasi pengembangan minat dan bakat khusus pada siswa agar dapat dikelola dengan baik, efisien dan efektif oleh guru dan digunakan oleh siswa. Menerapkan aplikasi sistem pakar dengan metode Certainty Factor untuk membantu proses identifikasi pengembangan minat dan bakat khusus pada siswa.

\section{Metodologi Penelitian}

\subsection{Subjek Penelitian}

Subjek pada penelitian yang dilakukan adalah penerapan sistem dalam identifikasi pengembangan minat dan bakat khusus pada siswa. Mengimplementasikan metode Certainty Factor untuk membantu proses identifikasi pengembangan minat dan bakat khusus pada siswa dan merancang sistem pakar menggunakan bahasa pemrograman $P H P$ dan database MYSQL.

\subsection{Sistem Pakar}

Penelitian sistem pakar yang dilakukan adalah menggunakaan metode Certainty Factor (CF). Data kualitatif dipresentasikan sebagai derajat keyakinan (degree of belief) di dalam metode Certainty Factor [7]. Metode Certanty Factor bekerja dengan cara menunjukkan ukuran kepastian terhadap suatu fakta atau aturan. Metode Certanty Factor melakukan penalaran layaknya seorang pakar dalam mendapatkan nilai kepercayaan. Proses perhitungan metode Certanty Factor dilakukan dengan cara menghitung nilai perkalian antara nilai $\mathrm{CF}$ user dan nilai $\mathrm{CF}$ pakar maka akan menghasilkan nilai CF kombinasi. Nilai dari hasil CF kombinasi tertinggi tersebut yang akan menjadi keputusan akhir dari metode Certanty Factor [8].

Nilai CF (Rule) didapat dari interpretasi "term" dari pakar yang diubah menjadi nilai $\mathrm{CF}$ tertentu sesuai Tabel 1.

Tabel 1. Tabel Nilai Certainty Factor

\begin{tabular}{lll}
\hline No & Uncertain Term & Nilai CF \\
\hline 1. & Pasti Tidak & 0 \\
2. & Hampir Pasti Tidak & 0,1 \\
3. & Kemungkinan Besar Tidak & 0,2 \\
4. & Mungkin Tidak & 0,3 \\
5. & Tidak Tahu & 0,4 \\
6. & Mungkin & 0,5 \\
7. & Kemungkinan Besar & 0,6 \\
8. & Hampir Pasti & 0,8 \\
9. & Pasti & 1 \\
\hline
\end{tabular}

\subsection{Kerangka Penelitian}

Langkah-langkah yang diambil dalam penelitian ini agar tidak melenceng dari pokok pembahasan dan lebih mudah dipahami, maka urutan langkah-langkah akan dibuat secara sistematis sehingga dapat dijadikan pedoman yang jelas dan mudah untuk menyelesaikan permasalahan yang ada [9]. Gambar 1 menunjukan urutan langkah-langkah yang akan dibuat pada penelitian ini dapat dilihat sebagai berikut:

Sistem pakar (expert system) merupakan salah satu bagian dari kecerdasan buatan (Artificial Intelligence) yang khusus untuk memecahkan permasalahan dan memberikan solusi di tingkat ahli dengan menggunakan pengetahuan. Topik riset ilmu komputer dalam AI (Artificial Intelligence) merupakan area penelitian yang sangat dinamis [5]. Konsep dasar sistem pakar adalah keahlian yang ditransfer ke suatu komputer, keahlian yang berupa pengetahuan tersebut disimpan dan nantinya dapat digunakan oleh sistem agar mencarikan solusi dari fakta-fakta yang didapatkan. Tujuan utama dari sistem pakar tidaklah menggantikan peran seorang pakar atau seorang ahli, tetapi lebih sebagai penghubung antara seorang pakar dengan user yang membutuhkan pengetahuan dibidang kepakaran

Jurnal Sistim Informasi dan Teknologi Vol. 3 No. 2 (2021) 48-52 


\begin{tabular}{|c|}
\hline Mendeskripsikan Ruang Lingkup Masalah \\
\hline$\checkmark$ \\
\hline Menganalisa Permasalahan \\
\hline 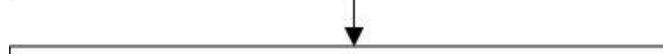 \\
\hline Mempelajari Studi Literatur \\
\hline$\checkmark$ \\
\hline Mengumpulkan Data \\
\hline$\downarrow$ \\
\hline $\begin{array}{l}\text { Menganalisa Data Menggunakan Metode Certainty Factor } \\
\text { 1. Mengumpulkan data } \\
\text { 2. Membentuk tabel keputusan } \\
\text { 3. Membangun aturan (rule) } \\
\text { 4. Membuat pohon pelacakan }\end{array}$ \\
\hline$\checkmark$ \\
\hline Merancang Sistem \\
\hline 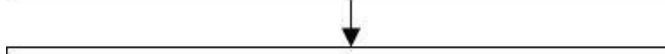 \\
\hline Mengimplementasikan Sistem \\
\hline$\nabla$ \\
\hline Hasil Identifikasi \\
\hline
\end{tabular}

Agar terincinya kerangka kerja diatas, maka akan dijelaskan alur penelitian sebagai berikut [10] [11] [13] [14] [15]:

a. Mendeskripsikan Ruang Lingkup Masalah

Ruang lingkup masalah yang akan diteliti harus ditentukan terlebih dahulu, agar mampu menjelaskan dan menentukan ruang lingkup yang akan diteliti. Mendeskripsikan ruang lingkup masalah ini merupakan langkah awal dalam melakukan penulisan ini.

b. Menganalisa Permasalahan

Menganalisa permasalahan merupakan alur berikutnya agar penelitian yang akan dilakukan dapat memahami masalah yang telah ditentukan batasan masalahnya. Pada analisa masalah ini digambarkan proses untuk mengidentifikasi minat dan bakat khusus berdasarkan ciri-ciri minat dan bakat khusus. Hasil analisis masalah ini diharapkan sistem pakar yang dibangun hendaknya mampu memberikan pengetahuan dalam mengidentifikasi pengembangan minat dan bakat khusus pada siswa.

c. Mempelajari Literatur

Mempelajari literatur juga sangat penting dilakukan agar mempunyai landasan baik secara teoritis yang benar dan jelas yang telah dijelaskan oleh para peneliti dan ahli sebelumnya. Kegiatan studi literatur yang lakukan dalam penelitian ini adalah mencari literatur yang berkaitan seperti melakukan review jurnal, mencari informasi dibuku dan jurnal yang berkaitan dengan penelitian agar penelitian ini nantinya dapat dipertanggung jawabkan dan mengamati kondisi di lapangan dengan cara melihat, mempelajari dan memahami permasalahan tentang minat dan bakat khusus dengan mengumpulkan data-data minat dan bakat khusus.

d. Mengumpulkan Data
Mengumpulkan data dilakukan untuk dapat memperoleh informasi data-data yang dibutuhkan dalam penelitian untuk mencapai tujuan penelitian. Pada metode penelitian ini peneliti menggunakan beberapa metode penelitian dalam pengumpulan data, yaitu field research dan teknik kalkulasi. Field Reseach merupakan sebuah metode penelitian agar dapat menghasilkan data yang optimal, maka diperlukan penilitian lapangan, dimana penelitian lapangan ini melakukan pengambilan data secara langsung. Teknik kalkulasi adalah menghitung data yang tersedia untuk menghasilkan informasi yang berguna di dalam penelitian ini.

e. Menganalisa Data Menggunakan Metode Certainty Factor

Permasalahan penelitian ini dapat dianalisa dengan menggunakan metode Certainty Factor, dengan harapan untuk menentukan identifikasi pengembangan minat dan bakat khusus pada siswa tersebut dapat dikelola dengan baik, efisien dan efektif.

f. Merancang Sistem

Merancang sistem merupakan rancangan awal sebelum sistem itu digunakan. Hasil dari tahapan ini nantinya menghasilkan sebuah sistem yang dapat digunakan untuk memproses analisa penelitian secara terkomputerisasi.

g. Mengimplementasi Sistem

Sistem yang dirancang menggunakan bahasa pemrograman PHP yang menerapkan metode Certainty Factor. Implementasi ini dilakukan untuk membandingkan hasil yang didapatkan dengan analisa secara manual dengan sistem.

h. Hasil Identifikasi

Tahap ini dilakukan untuk menguji data lama dengan data yang baru bagai mana akurasinya. Tujuan tahap ini untuk mengetahui apakah diperoleh kesesuaian antara hasil output dari analisis aplikasi dengan perhitungan manual.

Analisa sistem bertujuan untuk memperoleh pengetahuan dan rule yang berhubungan dengan data yang diuji dan metode yang diterapkan. Berdasarkan kerangka kerja penelitian pada Gambar 1 guna memudahkan dalam analisa dan perancangan sistem maka perlu dibuat bagan alir analisa perancangan seperti Gambar 2 berikut:

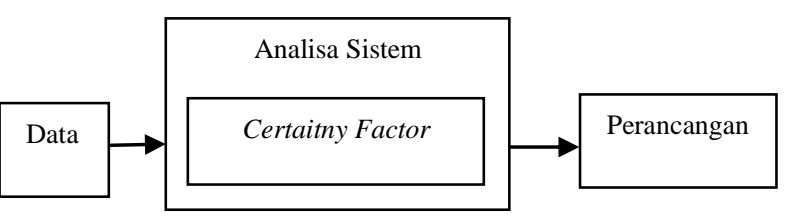

Gambar 2. Bagan Alir Analisa dan Perancangan

\section{Hasil dan Pembahasan}

Pada tahap analisa sistem ini diperlukan pengetahuan dan informasi yang diperoleh dari beberapa sumber, yaitu guru bimbingan konseling sebagai pakar dan

Jurnal Sistim Informasi dan Teknologi Vol. 3 No. 2 (2021) 48-52 
jurnal serta buku yang terkait dengan data jenis minat dan bakat khusus dan data ciri-ciri minat dan bakat khusus.

\subsection{Analisa Data}

Berdasarkan hasil pengumpulan data dari guru bimbingan konseling sebagai pakar, maka diperoleh 5 jenis data minat dan bakat khusus. Setiap jenis data minat dan bakat khusus diberikan kode berupa huruf dan angka seperti pada Tabel 2 berikut:

Tabel 2. Data Jenis Minat dan Bakat Khusus

\begin{tabular}{cll}
\hline No & $\begin{array}{l}\text { Kode Minat dan } \\
\text { Bakat Khusus }\end{array}$ & Jenis Minat dan Bakat Khusus \\
\hline 1. & B01 & Bakat Akademik Khusus \\
2. & B02 & Bakat Kreatif dan Produktif \\
3. & B03 & Bakat Seni \\
4. & B04 & Bakat Kinestetik/Psikomotorik \\
5. & B05 & Bakat Sosial
\end{tabular}

Berdasarkan hasil pengumpulan data minat dan bakat khusus dari pakar diperoleh kesimpulan terdapat 16 data ciri-ciri. Setiap data ciri-ciri minat dan bakat khusus diberikan kode berupa huruf dan angka seperti pada Tabel 3.

Tabel 3. Data Ciri-Ciri Minat dan Bakat Khusus

\begin{tabular}{|c|c|c|}
\hline No & $\begin{array}{l}\text { Kode } \\
\text { Ciri-Ciri }\end{array}$ & Ciri-Ciri Minat dan Bakat Khusus \\
\hline 1. & $\mathrm{C} 01$ & Mempunyai dorongan ingin tau besar \\
\hline 2. & $\mathrm{C} 02$ & Mudah memahami irama lagu \\
\hline 3. & $\mathrm{C} 03$ & Suka berada di antara banyak orang \\
\hline 4. & $\mathrm{C} 04$ & Suka membaca buku \\
\hline 5 . & $\mathrm{C} 05$ & Suka berfikir positif \\
\hline 6. & $\mathrm{C} 06$ & Suka menganalisa \\
\hline 7. & $\mathrm{C} 07$ & Suka menghitung angka \\
\hline 8. & $\mathrm{C} 08$ & $\begin{array}{l}\text { Suka memberikan banyak gagasan dan } \\
\text { usul terhadap suatu masalah }\end{array}$ \\
\hline 9. & $\mathrm{C} 09$ & Suka menari \\
\hline 10. & $\mathrm{C} 10$ & Cermat dalam pengamatan \\
\hline 11. & C11 & Suka befikir kritis \\
\hline 12. & $\mathrm{C} 12$ & Suka menirukan gerak \\
\hline 13. & $\mathrm{C} 13$ & Suka mencoba hal-hal yang baru \\
\hline 14. & $\mathrm{C} 14$ & Aktif dalam kegiatan fisik \\
\hline 15. & $\mathrm{C} 15$ & $\begin{array}{l}\text { Suka belajar atau bekerja dengan baik } \\
\text { seorang diri }\end{array}$ \\
\hline 16. & $\mathrm{C} 16$ & Suka melakukan penelitian \\
\hline
\end{tabular}

\subsection{Menentukan Rule}

Rule merupakan teknik representasi pengetahuan sintax rule IF E Then H. Evidence atau fakta yang ada serta hipotesa atau kesimpulan yang dihasilkan, berdasarkan hasil pengolahan data ciri-ciri dan data jenis minat dan bakat khusus maka diperoleh 24 rule untuk alternatif minat dan bakat khusus yang dapat dilihat pada Tabel 4.
Tabel 4. Rule

\begin{tabular}{|c|c|c|}
\hline No & Rule & Nilai $\mathrm{CF}$ \\
\hline 1. & $\begin{array}{l}\text { IF C01 AND C04 AND C05 AND C06 AND C07 } \\
A N D \text { C08 AND C10 AND C11 AND C15 AND } \\
\text { C16 THEN B01 }\end{array}$ & 1.0 \\
\hline 2. & $\begin{array}{l}\text { IF C01 AND C04 AND C05 AND C06 AND C07 } \\
\text { THEN B01 }\end{array}$ & 0.70 \\
\hline 3. & $\begin{array}{l}\text { IF C01 AND C05 AND C06 AND C08 AND C10 } \\
A N D \text { C11 AND C15 THEN B01 }\end{array}$ & 0.90 \\
\hline 4. & $\begin{array}{l}\text { IF C01 AND C04 AND C07 AND C10 AND C11 } \\
A N D \text { C15 AND C16 THEN B01 }\end{array}$ & 0.60 \\
\hline 5. & $\begin{array}{l}\text { IF C01 AND C05 AND C08 AND C10 THEN } \\
\text { B01 }\end{array}$ & 0.50 \\
\hline 6. & $\begin{array}{l}\text { IF C01 AND C05 AND C08 AND C10 AND C11 } \\
A N D \text { C16 THEN B01 }\end{array}$ & 0.80 \\
\hline 7. & $\begin{array}{l}\text { IF C01 AND C04 AND C05 AND C06 AND C07 } \\
A N D \text { C10 AND C11 AND C13 AND C16 THEN } \\
\text { B02 }\end{array}$ & 1.00 \\
\hline 8. & $\begin{array}{l}\text { IF C01 AND C04 AND C05 AND C06 AND C07 } \\
A N D \text { C13 THEN B02 }\end{array}$ & 0.80 \\
\hline 9. & $\begin{array}{l}\text { IF C01 AND C10 AND C11 AND C13 AND C16 } \\
\text { THEN B02 }\end{array}$ & 0.50 \\
\hline 10. & $\begin{array}{l}\text { IF C01 AND C06 AND G7 AND C10 AND C11 } \\
A N D \text { C13 THEN B02 }\end{array}$ & 0.70 \\
\hline 11. & $\begin{array}{l}\text { IF C01 AND C02 AND C03 AND G5 AND G6 } \\
A N D \text { C09 AND C11 AND C12 AND C15 THEN } \\
\text { B03 }\end{array}$ & 1.00 \\
\hline 12. & $\begin{array}{l}\text { IF C01 AND C02 AND C03 AND C05 AND C06 } \\
\text { AND C09 THEN B03 }\end{array}$ & 0.70 \\
\hline 13. & $\begin{array}{l}\text { IF C01 AND C03 AND C06 AND C09 AND C11 } \\
\text { AND C12 AND C15 THEN B03 }\end{array}$ & 0.80 \\
\hline 14. & $\begin{array}{l}\text { IF C01 AND C02 AND C03 AND C11 AND C15 } \\
\text { THEN B03 }\end{array}$ & 0.50 \\
\hline 15. & $\begin{array}{l}\text { IF C03 AND C05 AND C09 AND C12 AND C14 } \\
\text { THEN B04 }\end{array}$ & 1.00 \\
\hline 16. & $\begin{array}{l}\text { IF C03 AND C05 AND C09 AND C12 THEN } \\
\text { B04 }\end{array}$ & 0.80 \\
\hline 17. & $\begin{array}{l}\text { IF C03 AND C05 AND C09 AND C14 THEN } \\
\text { B04 }\end{array}$ & 0.70 \\
\hline 18. & $\begin{array}{l}\text { IF C05 AND C09 AND C12 AND C14 THEN } \\
\text { B04 }\end{array}$ & 0.60 \\
\hline 19. & $\begin{array}{l}\text { IF C03 AND C09 AND C12 AND C14 THEN } \\
\text { B04 }\end{array}$ & 0.90 \\
\hline 20. & $\begin{array}{l}\text { IF C01 AND C03 AND C04 AND C05 AND C06 } \\
A N D \text { C07 AND C08 AND C11 AND C15 AND } \\
\text { C16 THEN B05 }\end{array}$ & 1.00 \\
\hline 21. & $\begin{array}{l}\text { IF C01 AND C03 AND C05 AND C06 AND C11 } \\
A N D \text { C15 AND C16 THEN B05 }\end{array}$ & 0.70 \\
\hline 22. & $\begin{array}{l}\text { IF C01 AND C04 AND C05 AND C06 AND C07 } \\
A N D \text { C08 AND C11 AND C16 THEN B05 } \\
\text { IF C01 AND C03 AND C06 THEN B05 }\end{array}$ & 0.80 \\
\hline $\begin{array}{l}23 . \\
24 .\end{array}$ & $\begin{array}{l}\text { IF C01 AND C03 AND C06 AND C15 AND C16 } \\
\text { THEN B05 }\end{array}$ & $\begin{array}{l}0.50 \\
0.80\end{array}$ \\
\hline
\end{tabular}

Berdasarkan rule pada Tabel 4 maka akan dilakukan proses dialog siswa dengan Sistem Pakar yang dapat dilihat pada Tabel 5. 
Tabel 5. Fakta Ciri-Ciri Minat dan Bakat Khusus

\begin{tabular}{|c|c|c|}
\hline $\begin{array}{l}\text { Kode } \\
\text { Ciri }\end{array}$ & Pertanyaan & Jawaban \\
\hline $\mathrm{C} 01$ & $\begin{array}{l}\text { Apakah anda mempunyai } \\
\text { dorongan ingin tau besar? }\end{array}$ & $\begin{array}{l}\mathrm{Ya} \\
(\mathrm{CF}=0.80)\end{array}$ \\
\hline $\mathrm{C} 02$ & $\begin{array}{l}\text { Apakah anda mudah } \\
\text { memahami irama lagu? }\end{array}$ & $\begin{array}{l}\mathrm{Ya} \\
(\mathrm{CF}=0.60)\end{array}$ \\
\hline $\mathrm{C} 03$ & $\begin{array}{l}\text { Apakah anda suka berada di } \\
\text { antara banyak orang? }\end{array}$ & $\begin{array}{l}\text { Ya } \\
(\mathrm{CF}=0.80)\end{array}$ \\
\hline $\mathrm{C} 04$ & $\begin{array}{l}\text { Apakah anda suka membaca } \\
\text { buku? }\end{array}$ & $\begin{array}{l}\mathrm{Ya} \\
(\mathrm{CF}=0.60)\end{array}$ \\
\hline $\mathrm{C} 05$ & $\begin{array}{l}\text { Apakah anda suka berfikir } \\
\text { positif? }\end{array}$ & $\begin{array}{l}\mathrm{Ya} \\
(\mathrm{CF}=0.70)\end{array}$ \\
\hline $\mathrm{C} 06$ & $\begin{array}{l}\text { Apakah anda suka } \\
\text { menganalisa? }\end{array}$ & $\begin{array}{l}\mathrm{Ya} \\
(\mathrm{CF}=0.80)\end{array}$ \\
\hline $\mathrm{C} 07$ & $\begin{array}{l}\text { Apakah anda suka menghitung } \\
\text { angka? }\end{array}$ & $\begin{array}{l}\mathrm{Ya} \\
(\mathrm{CF}=0.60)\end{array}$ \\
\hline $\mathrm{C} 08$ & $\begin{array}{l}\text { Apakah anda suka memberikan } \\
\text { banyak gagasan dan usul } \\
\text { terhadap suatu masalah? }\end{array}$ & $\begin{array}{l}\mathrm{Ya} \\
(\mathrm{CF}=0.60)\end{array}$ \\
\hline C09 & Apakah anda suka menari? & $\begin{array}{l}\mathrm{Ya} \\
(\mathrm{CF}=0.80)\end{array}$ \\
\hline $\mathrm{C} 10$ & $\begin{array}{l}\text { Apakah anda cermat dalam } \\
\text { pengamatan? }\end{array}$ & $\begin{array}{l}\mathrm{Ya} \\
(\mathrm{CF}=0.50)\end{array}$ \\
\hline C11 & $\begin{array}{l}\text { Apakah anda suka befikir } \\
\text { kritis? }\end{array}$ & Tidak \\
\hline $\mathrm{C} 12$ & $\begin{array}{l}\text { Apakah anda suka menirukan } \\
\text { gerak? }\end{array}$ & Tidak \\
\hline $\mathrm{C} 13$ & $\begin{array}{l}\text { Apakah anda suka mencoba } \\
\text { hal-hal yang baru? }\end{array}$ & $\begin{array}{l}\mathrm{Ya} \\
(\mathrm{CF}=0.60)\end{array}$ \\
\hline C14 & $\begin{array}{l}\text { Apakah anda aktif dalam } \\
\text { kegiatan fisik? }\end{array}$ & $\begin{array}{l}\text { Ya } \\
(\mathrm{CF}=0.80)\end{array}$ \\
\hline $\mathrm{C} 15$ & $\begin{array}{l}\text { Apakah anda suka belajar atau } \\
\text { bekerja dengan baik seorang } \\
\text { diri? }\end{array}$ & Tidak \\
\hline C16 & $\begin{array}{l}\text { Apakah anda suka melakukan } \\
\text { penelitian? }\end{array}$ & Tidak \\
\hline
\end{tabular}

$\mathrm{C} 07(\mathrm{CF}=0.60) \quad$ AND $\mathrm{C} 13(\mathrm{CF}=0.60)$
$\mathrm{B} 02(\mathrm{CF}=0.80)$
$\begin{aligned} \mathrm{CF} 1(\mathrm{C} 01 . \mathrm{C} 04 . \mathrm{C} 05 . \mathrm{C} 06 . \mathrm{C} 07 . \mathrm{C} 13 \cap \mathrm{B} 02) \\ \quad=\mathrm{Min}[0.80 ; 0.60 ; 0.60 ; 0,80 ; 0,60 ; 0.60] * 0,80 \\ \quad=0,48\end{aligned}$
Rule $9=$ Tidak dieksekusi karena Envidence Tidak Fakta

Rule $\mathbf{1 0}=$ Tidak dieksekusi karena Envidence Tidak

Fakta

Fakta Baru:

B02 Hypothesis $\mathrm{CF}=0.48$

Rule $\mathbf{1 1}$ = Tidak dieksekusi karena Envidence Tidak Fakta

Rule 12 = IF C01 $(\mathrm{CF}=0.80)$ AND $\mathrm{C} 02(\mathrm{CF}=0.60) A N D$

$\mathrm{C} 03(\mathrm{CF}=0.80) \quad A N D \quad \mathrm{C} 05(\mathrm{CF}=0.60) \quad A N D$

$\mathrm{C} 06(\mathrm{CF}=0.80) \quad A N D \quad \mathrm{C} 09(\mathrm{CF}=0.80) \quad$ THEN

$\mathrm{B} 03(\mathrm{CF}=0.70)$

CF1 (C01.C02.C03.C05.C06.C09 ค B03)

$$
=\operatorname{Min}[0.80 ; 0.60 ; 0.80 ; 0.60 ; 0.80 ; 0.80] * 0.70
$$$$
=0.42 \text {. }
$$

Rule $\mathbf{1 3}$ = Tidak dieksekusi karena Envidence Tidak Fakta

Rule 14 = Tidak dieksekusi karena Envidence Tidak Fakta

Fakta Baru:

B03 Hypothesis $\mathrm{CF}=0.42$

Rule $\mathbf{1 5}$ = Tidak dieksekusi karena Envidence Tidak Fakta

Rule 16 = Tidak dieksekusi karena Envidence Tidak Fakta

Rule 17 = IF C03 $(\mathrm{CF}=0.80)$ AND $\mathrm{C} 05(\mathrm{CF}=0.60) A N D$ $\mathrm{C} 09(\mathrm{CF}=0.80) \quad$ AND $\quad \mathrm{C} 14(\mathrm{CF}=0.80) \quad$ THEN $\mathrm{B} 04(\mathrm{CF}=0.70)$

Keterangan setiap rule dari fakta baru:

Rule $\mathbf{1}$ = Tidak dieksekusi karena Envidence Tidak CF1 (C03.C05.C09.C14 @ B04)

Fakta

Rule 2 = IF C01 $(\mathrm{CF}=0.80) A N D \mathrm{C} 04(\mathrm{CF}=0.60) A N D$ $=\operatorname{Min}[0.80 ; 0.60 ; 0.80 ; 0,80] * 0.70$ $=0.42$
$\mathrm{C} 05(\mathrm{CF}=0.60) \quad A N D \quad \mathrm{C} 06(\mathrm{CF}=0.80)$

$\mathrm{C} 07(\mathrm{CF}=0.60)$ THEN B01 $(\mathrm{CF}=0.70)$

CF1 (C01.C04.C05.C06.C07 ค B01)

$$
=\operatorname{Min}[0.80 ; 0.60 ; 0.60 ; 0,80 ; 0,60] * 0,70
$$$$
=0,42
$$

AND Rule 18 = Tidak dieksekusi karena Envidence Tidak Fakta

Rule 19 = Tidak dieksekusi karena Envidence Tidak Fakta

Fakta Baru:

Rule 3 = Tidak dieksekusi karena Envidence Tidak B04 Hypothesis $\mathrm{CF}=0.42$

Fakta

Rule 20 = Tidak dieksekusi karena Envidence Tidak

Rule 4 = Tidak dieksekusi karena Envidence Tidak Fakta

Fakta

Rule 21 = Tidak dieksekusi karena Envidence Tidak

Rule 5 = IF C01 $(\mathrm{CF}=0.80)$ AND $\mathrm{C} 05(\mathrm{CF}=0.60$ AND Fakta

$\mathrm{C} 08(\mathrm{CF}=0.60) \quad A N D \quad \mathrm{C} 10(\mathrm{CF}=0.50) \quad$ THEN Rule $22=\mathrm{IF} \mathrm{C} 01(\mathrm{CF}=0.80) A N D \mathrm{C} 04(\mathrm{CF}=0.60) A N D$

$\mathrm{B} 01(\mathrm{CF}=0.50)$

CF1 (C01.C05.C08.C10 ค B01)

$$
\begin{aligned}
& =\operatorname{Min}[0.80 ; 0.60 ; 0.60 ; 0,50] * 0,50 \\
& =0,25
\end{aligned}
$$

Rule 6 = Tidak dieksekusi karena Envidence Tidak

Fakta

Fakta Baru:

B01 Hypothesis $\mathrm{CF}=0.42$

B01 Hypothesis $\mathrm{CF}=0.25$

$\mathrm{C} 05(\mathrm{CF}=0.60) A N D \mathrm{C} 06(\mathrm{CF}=0.80) A N D$

$$
\begin{aligned}
& \mathrm{C} 07(\mathrm{CF}=0.60) \quad A N D \quad \mathrm{C} 08(\mathrm{CF}=0.60) \\
& \mathrm{THEN} \mathrm{B} 05(\mathrm{CF}=0.60)
\end{aligned}
$$

CF1 (C01.C04.C05.C06.C07.C08.C11.C16 ค B01)

$0,60] * 0,60$ $=\operatorname{Min}[0.80 ; 0.60 ; 0,70 ; 0,80 ; 0,60 ; 0,60 ; 0,60$;

Rule 7 = Tidak dieksekusi karena Envidence Tidak CF1 (C01.C03.C06 ? B01)

Fakta

Rule 8 = IF C01 $(\mathrm{CF}=0.80)$ AND $\mathrm{C} 04(\mathrm{CF}=0.60) A N D$ $=0,36$

Rule 23 = IF $\mathrm{C} 01(\mathrm{CF}=0.80) A N D \mathrm{C} 03(\mathrm{CF}=0.80) A N D$

$\mathrm{C} 06(\mathrm{CF}=0.80)$ THEN B05(CF=0.50)

$\mathrm{C} 05(\mathrm{CF}=0.60) \quad A N D \quad \mathrm{C} 06(\mathrm{CF}=0.80)$

$$
\begin{aligned}
& =\operatorname{Min}[0.80 ; 0.80 ; 0,80] * 0,50 \\
& =0,40
\end{aligned}
$$

AND Rule $\mathbf{2 4}=$ Tidak dieksekusi karena Envidence Tidak Fakta

Jurnal Sistim Informasi dan Teknologi Vol. 3 No. 2 (2021) 48-52 
Fakta Baru:

B05 Hypothesis $\mathrm{CF}=0.36$

$\mathrm{B} 05$ Hypothesis $\mathrm{CF}=0.40$

\begin{tabular}{lll} 
& \multicolumn{2}{c}{ Tabel 6. Fakta Baru Tipe } \\
\hline Fakta Baru & & Nilai CF \\
\hline B01 & Hypothesis & 0.42 \\
B01 & Hypothesis & 0.25 \\
B02 & Hypothesis & 0.48 \\
B03 & Hypothesis & 0.42 \\
B04 & Hypothesis & 0.42 \\
B05 & Hypothesis & 0.36 \\
B05 & Hypothesis & 0.40 \\
\hline
\end{tabular}

CF Gabungan dari Rule:

Karena R2 dan R5 Hipotesanya sama yaitu B01, maka $\mathrm{CF}$ digabungkan:

$$
\begin{aligned}
\mathrm{CF}=\mathrm{CF} 1 & +\mathrm{CF} 2 \times(1-\mathrm{CF} 1) \\
& =0.42+0.25 \times(1-0.42) \\
& =0.56
\end{aligned}
$$

Karena R22 dan R23 Hipotesanya sama yaitu B05, maka CF digabungkan:

$$
\begin{aligned}
\mathrm{CF}=\mathrm{CF} 1 & +\mathrm{CF} 2 \times(1-\mathrm{CF} 1) \\
& =0.36+0.40 \times(1-0.36) \\
& =0.61
\end{aligned}
$$

\section{Fakta Baru:}

B01 Hypothesis $\mathrm{CF}=0.56 * 100=58 \%$

B05 Hypothesis $\mathrm{CF}=0.61 * 100=61 \%$

\section{Kesimpulan:}

Minat dan bakat khusus yang dipilih oleh siswa adalah: Bakat sosial dengan Tingkat Kepastian $=0.61$ atau $61 \%$.

\subsection{Hasil}

Guna menghitung nilai probabilitas hingga mendapatkan tingkat akurasi Sistem Pakar dalam identifikasi pengembangan minat dan bakat khusus pada siswa menggunakan metode Certainty Factor, maka dilakukan dengan peritungan menggunakan rumus probalilitas sebagai berikut:

Rumus Probabilitas: $P_{(E)}=\frac{X}{N} \times 100 \%$

Keterangan:

P: Probalilitas;

E: Event;

$\mathrm{X}$ : Jumlah kejadian yang terjadi;

$\mathrm{N}$ : Jumlah seluruh kejadian.

Seperti yang telah dijelakan bahwa penilaian keakuratan sistem terdiri dari 2 level, yaitu level 0 dan level 1. Level 0 diberikan jika hasil konseling sistem tidak sama dengan hasil konseling pakar dan level 1 diberikan jika konseling sistem sama dengan hasil konseling pakar, maka pada kasus penelitian ini dapat dihitung probabilitasnya diperoleh hasil sebagai berikut:

$$
\begin{aligned}
\text { (Akurat) } & =\frac{X}{N} \times 100 \% \\
= & 4 / 5 \times 100 \% \\
= & 80 \%
\end{aligned}
$$

$($ Tidak akurat $)=\mathrm{x} 100 \%$

$=1 / 5 \times 100 \%$

$=20 \%$

Dari hasil probabilitas maka nilai akurasi sistem dengan hasil keputusan pakar mencapai $80 \%$ dalam identifikasi pengembangan minat dan bakat khusus pada siswa menggunakan metode Certainty Factor. Hasil terhadap penelitian ini adalah jenis minat dan bakat khusus pada siswa dan stimulasi untuk siswa. Setelah dilakukan pengujian dan perhitungan tingkat akurasi sistem, maka didapatkan tingkat akurasi yang baik dari hasil perhitungan sistem dengan keputusan pakar sebesar $80 \%$ dari 5 data pengujian.

Gambar 3 menampilkan menu utama siswa merupakan form tempat siswa untuk dapat masuk kedalam sistem dan melakukan proses konseling, dalam form menu utama siswa untuk pilihan sub menu lain yaitu menu informasi, registrasi dan login.

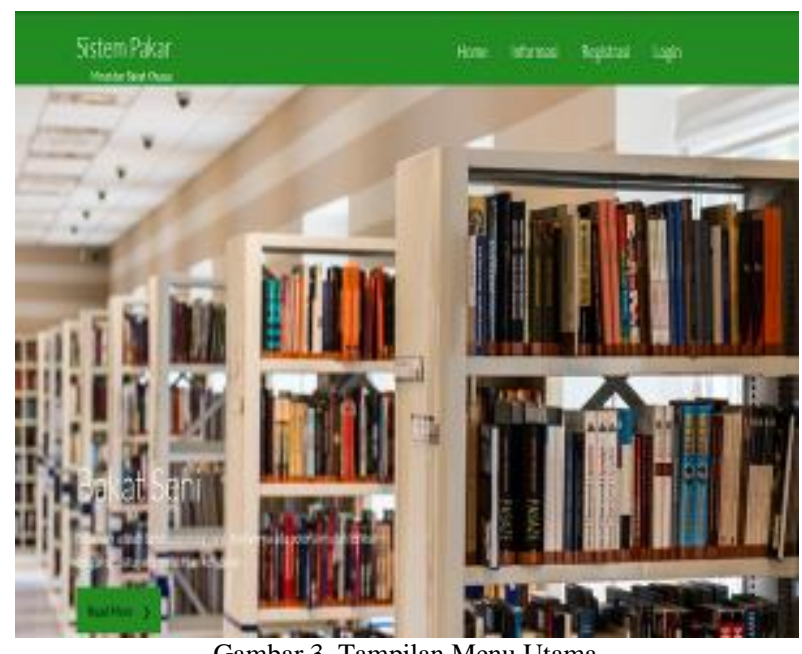

Gambar 3. Tampilan Menu Utama

Gambar 4 menampilkan tampilan registrasi yang ada didalam sistem, dimana siswa dapat melakukan registrasi agar dapat melakukan proses konseling pada sistem dan dapat menjadi member. 
Nandra Sunaryo, Yuhandri Yunus, Sumijan.

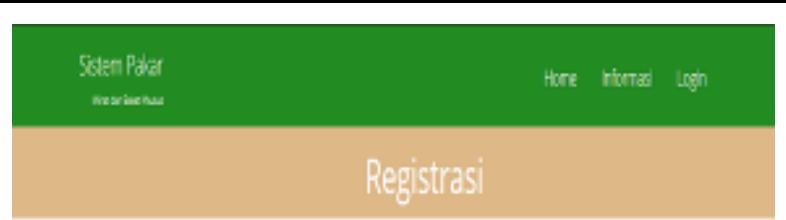
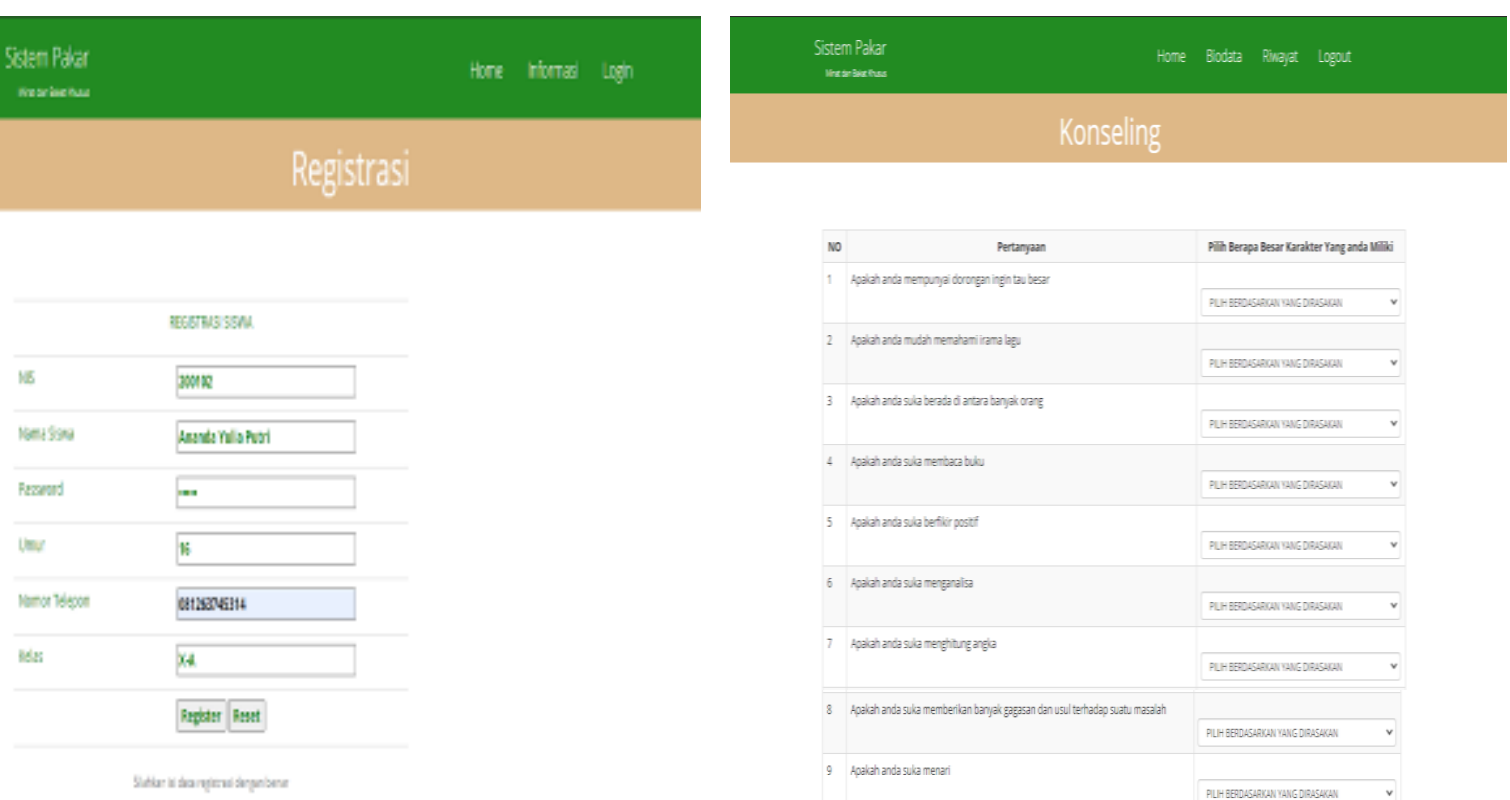

Gambar 4. Form Registrasi pada Siswa

Gambar 5 menampilkan tampilan login yang ada didalam sistem, dimana siswa dapat melakukan login agar dapat melakukan proses konseling pada sistem dan dapat menjadi member.

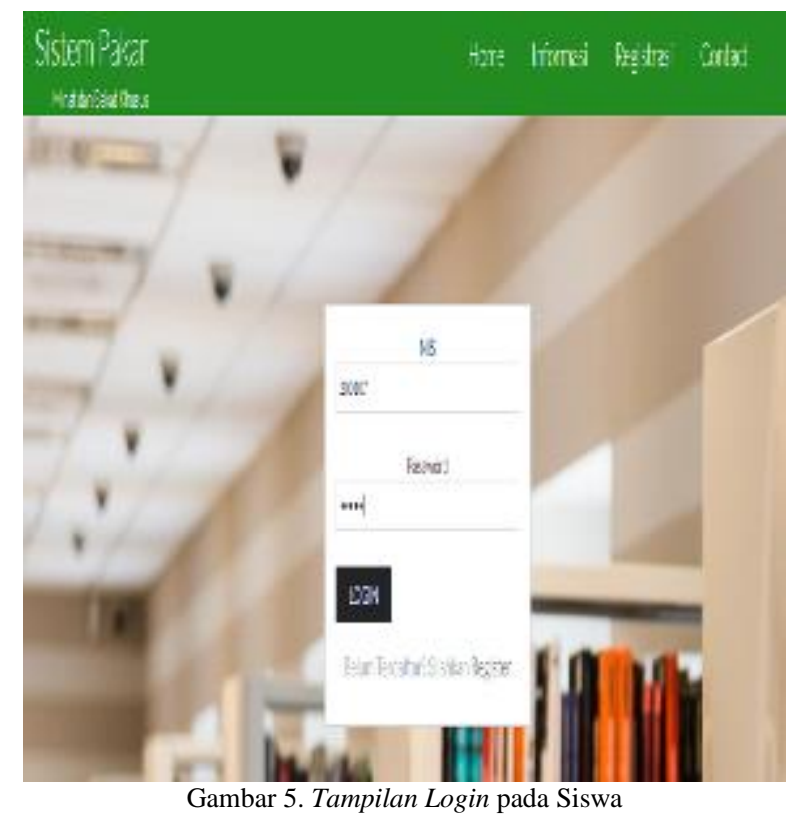

Gambar 6 menampilkan tampilan form konseling member dalam sistem, dimana sistem dapat menjawab daftar pertanyaan-pertanyaan yang ada pada sistem untuk mengetahui hasil konseling minat dan bakat khusus yang dialami oleh member pada Sistem Pakar.

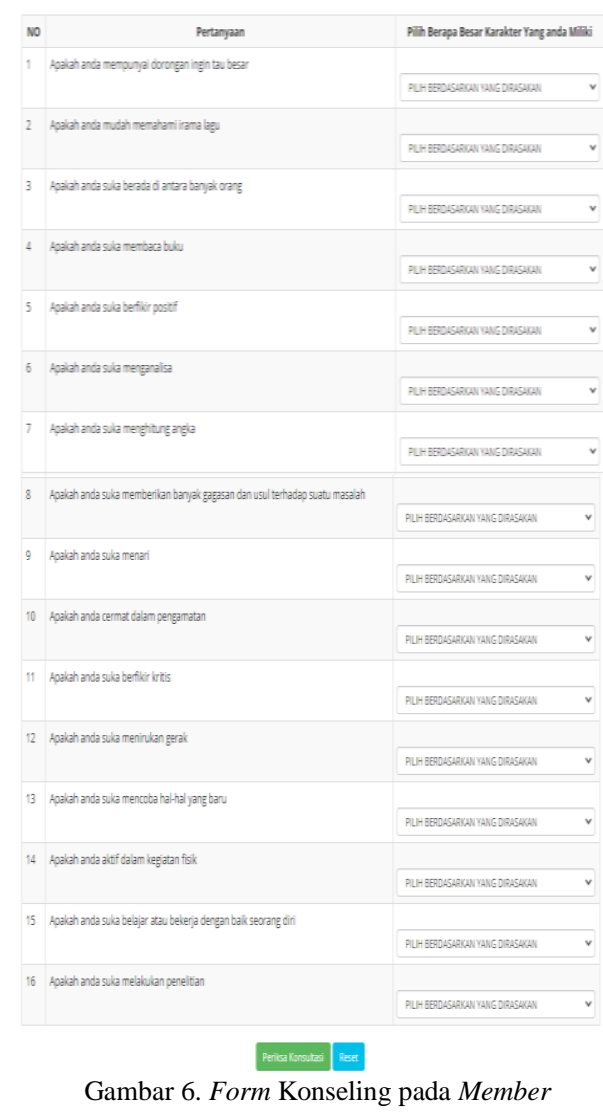

Gambar 7 menampilkan tampilan menu utama admin yang merupakan form tempat admin untuk dapat masuk kedalam sistem dan melakukan kelola data. Berikut dalam form menu utama admin untuk pilihan sub menu lain yaitu menu kelola data ciri-ciri, data minat dan bakat khusus, data siswa dan riwayat hasil konseling member.
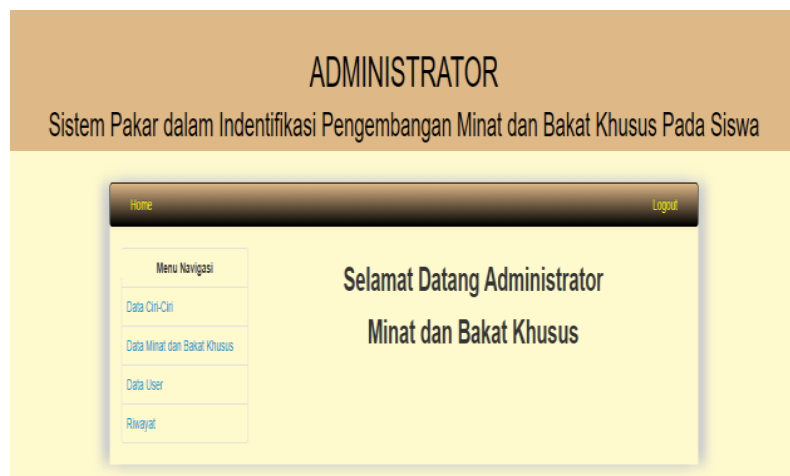

Gambar 7. Tampilan Menu Utama pada Admin

Jurnal Sistim Informasi dan Teknologi Vol. 3 No. 2 (2021) 48-52 


\section{Kesimpulan}

Adanya Sistem Pakar ini dapat membantu guru bimbingan konseling dalam melakukan konseling karena waktu yang tidak cukup disekolah, bagi siswa berguna untuk melakukan konseling tanpa harus bertemu dengan guru, siswa dapat mengetahui informasi tentang jenis minat dan bakat khusus, serta dapat menghasilkan informasi dan stimulasi yang tepat dan berguna. Hasil uji coba yang dilakukan dengan membandingkan data dengan sistem yang sudah dirancang maka didapatkan tingkat akurasi yang baik dari hasil perhitungan sistem dengan keputusan pakar sebesar $80 \%$ dari 5 data pengujian, sehingga sistem yang dirancang ini bisa digunakan untuk dijadikan alternatif dalam indentifikasi pengembangan minat dan bakat khusus pada siswa.

\section{Daftar Rujukan}

[1] Mulyani, E. D. S., Hidayat, C. R., \& Ulfa, T. C. (2018). Sistem Pakar Untuk Menentukan Jurusan Kuliah Berdasarkan Minat dan Bakat Siswa SMA dengan Menggunakan Metode Forward Chaining. CSRID Journal, 10(2), 80-92.

[2] Seputro, S. A., \& Masya, F. (2020). Assessment of Student's Interests and Talents Using The Web-Based Certainty Factor Method. Jurnal Riset Informatika, 2(3), 131-136. DOI: https://doi.org/10.34288/jri.v2i3.139 .

[3] Putri, N. A. (2018). Sistem Pakar Untuk Mengidentifikasi Kepribadian Siswa Menggunakan Metode Certainty Factor dalam Mendukung Pendekatan Guru. INTERCOMS: Journal of Information Technology and Computer Science, 1(1), 78-90. DOI: https://doi.org/10.31539/intecoms.v1i1.164 .

[4] Girsang, R. R., \& Fahmi, H. (2019). Sistem Pakar Mendiagnosa Penyakit Mata Katarak dengan Metode Certainity Factor Berbasis Web. MATIC Jurnal Ilmu Komputer dan Teknologi Informasi, 11(1), 27-31. https://doi.org/10.18860/mat.v11i1.7673.

[5] Habibie, D. R., \& Aldo, D. (2019). Sistem Pakar untuk Identifikasi Jenis Jerawat dengan Metode Certainity Factor. Journal of Information Technology and Computer Science (JOINTECS), 4(3), 79-86. https://doi.org/10.31328/jointecs.v4i3.1055 .
[6] Dian, R., Sumijan, S., \& Yunus, Y. (2020). Sistem Pakar dalam Identifikasi Kerusakan Gigi pada Anak dengan Menggunakan Metode Forward Chaining dan Certainty Factor. Jurnal Sistim Informasi dan Teknologi, 2(3), 65-70. DOI: http://doi.org/10.37034/jsisfotek.v2i3.36 .

[7] Putri, L. F. (2020). Perancangan Aplikasi Sistem Pakar Penyakit Roseola dengan Menggunakan Metode Certainty Factor. Jurnal Sistem Komputer dan Informatika (JSON), 1(2), 107-113. DOI: http://doi.org/10.30865/json.v1i2.1956 .

[8] Santi, I. H., \& Andari, B. (2019). Sistem Pakar Untuk Mengidentifikasi Jenis Kulit Wajah dengan Metode Certainty Factor. Intensif: Jurnal Ilmiah Penelitian dan Penerapan Teknologi Sistem Informasi, 3(2), 159-177. DOI: https://doi.org/10.29407/intensif.v3i2.12792.

[9] Yulianti, W., Trisnawati, L., \& Manullang, T. (2019). Sistem Pakar dengan Metode Certainty Factor dalam Penentuan Gaya Belajar Anak Usia Remaja. Jurnal Teknologi Informasi \& Komunikasi Digital Zone, 10(2), 120-130. DOI: https://doi.org/10.31849/digitalzone.v10i2.2781 .

[10] Irwan, I., Gustientiedina, G., Sunarti, S., \& Desnelita, Y. (2017). Perancangan Software Bimbingan dan Pengembangan Karir Siswa dalam Pengambilan Keputusan dan Konsultasi. Jurnal Teknologi Informasi dan Ilmu Komputer (JTIIK), 4(4), 237-243. DOI: http://dx.doi.org/10.25126/jtiik.201744464 .

[11]Hardianto, R., \& Kusuma, C. (2019). Rancang Bangun Sistem Pakar Penentuan Kepribadian. Jurnal Sistem Komputer dan Informatika (JSON), 1(1), 45-51. http://dx.doi.org/10.30865/json.v1i1.1385 .

[12]Masykur, R., Syazali, M., Nofrizal, N., \& Sugiharta, I. (2020). Model Matematika Pengambilan Keputusan Mahasiswa dalam Memilih Jurusan: Dampak Minat dan Bakat. Jurnal Pendidikan Matematika dan IPA, 11(1), 13-21. DOI: http://dx.doi.org/10.26418/jpmipa.v11i1.30885 .

[13] Khawarizmi, I. N., Triayudi, A., Sholihati, I. D. (2020). Diagnosa Depresi pada Mahasiswa Menggunakan Metode Certainty Factor dan Forward Chaining. Jurnal Inti Nusa Mandiri, 14(2), 139-144.

[14] Amin, P., Arini, D. U., Permadi, W. B. (2020). Memetakan Bakat dan Minat Siswa dengan Membangun Mental Wirausaha Guna Mendukung Program Ekonomi Kreatif di Lingkungan Sekolah. JMM (Jurnal Masyarakat Mandiri), 4(2), 308-318.

[15]Army, W. L., Yuhandri., \& Sumijan. (2018). Sistem Pakar Diagnosis Penyakit Menular dengan Metode Forward Chaining dan Certainty Factor. Jurnal Sains dan Informatika, 4(2), 171181. 